\title{
JURNALISME SANTRI MELAWAN HOAKS
}

\author{
Agus Fathuddin Yusuf \\ Dosen Fisip, Universitas Wahid Hasyim Semarang \\ Email: fathuddin@yahoo.com
}

\begin{abstract}
:
This article aims to increase awareness of the importance of journalism activities built by pesantren as one of the preaching efforts in the community through santri journalism (santri journalism), increase santri capacity to develop local religious communication and improve santri skills in making journalistic products in the form of news, features, opinions, and articles using social media-based information technology. This is important as an effort to increase the capacity of students as well as efforts to counter narrative lies (hoaks) through the development of citizen journalism in presenting information in the form of journalistic products including news, features, opinions, and articles. Through this, there was an increase in students' knowledge about various journalistic products, variants of information, social media as a form of media convergence, and an increase in the capacity of students as citizen journalists who were critical, caring and responsive to various types of events that occurred around them which were the basic things needed in journalistic work.
\end{abstract}

Keywords: journalism, santri, hoaks

\section{A. Pendahuluan}

Jurnalistik adalah bentuk komunikasi dari media massa, baik itu kegiatannya ataupun isinya, sedangkan pers adalah media tempat jurnalistik itu disalurkan. Kalau jurnalistik adalah hasil kegiatan pengolahan informasi yang akan disampaikan berupa berita, reportase, feature, dan opini, maka pers adalah surat kabarnya, atau majalahnya atau radionya atau televisinya. Singkat kata, pers adalah medianya, sedangkan jurnalistik adalah isinya (Ermanto, 2005:28).

Menurut Ermanto (2005:65), materi jurnalistik dalam media massa (cetak) secara fisiknya dapat dibagi menjadi dua kategori. Pertama, kategori berita-berita langsung, reportase, dan feature. Kedua, kategori pendapat atau opini-tajuk rencana, artikel dan tulisan kolom. Berita adalah sesuatu peristiwa yang terjadi dalam masyarakat yang menarik perhatian sejumlah orang. 
Berita juga bisa dikatakan laporan tentang ide, kejadian atau konflik yang menarik perhatian para pembaca yang membangkitkan minat dan mempunyai makna bagi pembaca dalam urusanurusannya atau hubungannya dengan masyarakat.

Sementara dewasa ini, kehadiran media online memunculkan "generasi baru" jurnalistik, yakni jurnalisme online (online journalism), disebut juga cyber journalism. Jurnalisme online merupakan proses penyampaian informasi dengan menggunakan media internet atau website (Romli, 2009: 97).

Dalam jurnalisme online inilah bereproduksi kabar bohong (hoax) yang bisa mengguncang ruang publik. Ruang publik sebagai aset interaksi sosial-pun bukan hanya terdefinisikan dalam alam nyata, melainkan lalu lalang dalam dunia maya. Bahkan arus info paling crowded justru terjadi dalam ruang publik gawai yang menobatkan media sosial sebagai panggung presentasi publik.

Bila lengah, pengguna dawai bisa terombang-ambing dalam buaian kepentingan penyebar hoaks. Imbasnya, bisa terjadi sebaran titik api (hot spot) yang berujung dentuman distorsi informasi yang siap menerkam emosi massa. Untuk itu, perlu pemahaman dan penyikapan yang cerdas atas perkembangan dunia digital yang bergerak sangat cepat.

\section{B. Pembahasan}

Menurut Wahyudi (1996: 3), fungsi kegiatan jurnalistik adalah menginformasikan fakta atau pendapat yang menganung nilai berita yang terjadi di tengah-tengah masyarakat, serta memberikan penjelasan masalah hangat melalui narasumber yang relevan untuk mengurangi atau meniadakan ketidakpastian yang ada di tengah masyarakat. Sedangkan dengan tugas jurnalistik 
adalah mengungkap fakta atau pendapat yang mengandung nilai berita, membela kebenaran dan keadilan, menjelaskan permasalahan hangat serta mendidik masyarakat agar lebih bersikap demokratis.

Sementara menurut Ermanto (2005: 25), jurnalistik pada intinya adalah kegiatan mengkomunikasikan informasi/ berita yang aktual kepada masyarakat melalui media massa secepat-cepatnya. Dari pengertian itu ada beberapa hal yang perlu dipahami. Pertama, jurnalistik merupakan proses/ kegiatan pengkomunikasian informasi/ berita, mulai dari mencari, mengumpulkan, mengolah, menulis dan mengedit informasi hingga menjadi berita yang aktual. Kedua, hasil olahan informasi itu bisa berwujud berita langsung, reportase, feuture, atau opini. Ketiga, informasi yang telah diolah itu disiarkan secepat-cepatnya melalui media massa seperti surat kabar, majalah atau televisi.

Padahal kegiatan jurnalistik menurut Undang-Undang No. 40 Tahun 1999 adalah kegiatan mencari, menghimpun, dan menyiarkan berita melalui media massa. Pola ini merupakan pola kerja yang dilakukan oleh setiap media yang berbasis jurnalistik santri, mulai dari tahap perencanaan, tahap peliputan, hingga tahap penyusunan laporan informasi. Pada tahapan pembahasan ini dibagi menjadi tiga, yakni : tahap persiapan materi, tahap sebaran dan pembentukan, dan tahap konfirmasi pemberitaan.

Sedangkan di sisi lain, modernisasi membawa perubahan yang kompleks bagi kehidupan masyarakat. Salah satunya pada aspek informasi dan komunikasi yang beriringan dengan mode interaksi dan relasi sosial. Pasca revolusi industri, teknologi media atau elektronik berkembang dan menjadi salah satu kebutuhan penting. Tidak hanya sebagai sarana bagi manusia untuk saling berinteraksi melainkan juga sarana untuk memperoleh informasi dan kebutuhan lainnya. Dengan 
demikian, teknologi informasi dan komunikasi atau yang sering disebut dengan information and communication technology (ICT) telah mengukuhkan diri sebagai piranti yang lekat pada kehidupan masyarakat era ini.

Teknologi elektronik telah bertranformasi menjadi medium yang memungkinkan individu terkoneksi dengan orang lain pada lintas batas teritori dan waktu serta membangun suatu ruang semu yang disebut dengan ruang maya. Ruang maya dan pola aktivitas di dalamnya telah membentuk suatu tatanan dan komunitas baru yang disebut dengan virtual community dan telah memberikan efek negatif yaitu hoax. Hoax dianggap meresahkan karena merupakan berita bohong yang digunakan untuk menarik opini massa demi kepentingan material. Jenis informasi hoax berbentuk gambar, foto, video, kartun, maupun berita.

Alhasil informasi palsu tersebut mampu menggiring interpretasi pengguna (user) sesuai dengan yang diharapkan oleh orang-orang yang memiliki kepentingan di dalamnya. Hoax begitu booming terutama didukung oleh pola penggunaan internet masyarakat yang lebih banyak untuk akses jejaring sosial dan instant messaging.

Hoax merupakan imbas dari perilaku mekanis sebagai konsekuensi atas masifnya teknologi dan media sosial. Kemudahan menerima, berbagi, dan memberi komentar melalui media sosial seperti facebook, twitter, whatsapps, dan sebagainya memperlihatkan bahwa informasi saling bertumpuk, berimplosif, dan berekplosif karena direproduksi melalui opsi share dan salin/copy yang tersedia dalam sistem media sosial. Bahkan setiap orang bisa mengomentari info yang diterima itu sesuka hati tanpa konfirmasi. Fenomena ini adalah bentuk dari 
hyperreality yaitu kenyataan yang berlebihan yang telah diprediksikan oleh Baudrillard puluhan tahun ketika istilah hoax belum dikenal ${ }^{1}$.

Hoax lebih marak di dunia maya dibandingkan media penyiaran mainstream seperti televisi, dalam artian mudah menyebar dan menarik follower setidaknya karena tiga alasan;

1. Dunia virtual yang ditunjukkan dengan adanya media sosial memberikan kebebasan bagi siapa pun untuk mengaksesnya tanpa batasan atau rule yang rumit seperti di masyarakat riil. Bahkan kita seolah menjadi masyarakat aktif yang dapat menanggapi dan membagikan apa yang dibaca melalui opsi berbagi (share) konten informasi dan link (alamat situs) yang kita peroleh kepada orang lain. Namun, hal itu -sayangnya- tidak diikuti dengan usaha untuk mengklarifikasi dan analisis yang memadai tentang isi berita dan sumber berita. Misal ada konten informasi atau link berita melalui whatsapps yang di bawahnya terdapat himbauan untuk membagikannya pada orang lain. Tanpa membaca secara detail dan analisis sumber berita secara otomatis pengguna mem-forwardnya ke grup whatsapps yang lain atau ke media sosial yang lain seperti BBM, Facebok, Line, dan sebagainya. Bisa dibayangkan jika setiap orang membagikan ke satu grup dan dilakukan berantai. Dalam hitungan jam, hoax bisa menyebar ke ribuan bahkan jutaan orang.

2. Media penyiaran mainstream seperti televisi lebih banyak dikuasi oleh orang atau golongan yang memiliki tendensi politis seperti yang tampak pada Pilpres Tahun 2014 yang mana kepentingan itu tampak pada media televisi yang juga melakukan koalisi. Hal itu menghilangkan netralitas dan merusak kepercayaan masyarakat terhadap media

\footnotetext{
${ }^{1}$ Kristi Poerwandari, Gaduh di Media. Kompas. Edisi 11 Februari 2017.
} 
penyiaran. Oleh karena itu masyarakat mulai beralih ke media sosial sebab di dalamnya mereka bisa menyampaikan opini dan berbagi secara bebas dan luas tanpa distorsi siapa pun dan dari mana pun. Keleluasaan yang kemudian cenderung keblablasan itulah menjadi akar dari munculnya hoax seperti saat ini.

3. Saat ini adalah eranya digital dan bertalian dengan poin kedua, maka tidak mengherankan jika booming-nya hoax juga ditentukan atau bahkan didukung dengan jumlah pengguna jaringan internet yang kian lama meningkat.

Pesantren merupakan salah satu bentuk pendidikan non formal berbasis agama islam sebagai pengganti dan juga pelengkap dari adanya pendidikan formal dalam penanaman nilainilai dan akhlak didalam proses pembelajarannya, sehingga melalui pondok peantren peserta didik dapat mengembangkan potensi, sikap, keterampilan, nilai-nilai keagamaan dan pengembangan nilai moral. Dimana, dalam perkembangannya selalu tumbuh dan berkembang. Menurut Sutarto (2013:11), "pada awalnya pendidikan nonformal berbentuk pondok pesantrian, yang sekarang dikenal dengan pondok pesantren, yang proses pembelajarannya diarahkan pada pengembangan potensi penge-tahuan, sikap, keterampilan, nilai-nilai keagamaan dan pengembangan nilai moral.”

Pendidikan didalam pondok pesantren bukan hanya selalu mengupas terkait hal keagamaan saja, tetapi juga menambahkan berbagai kegiatan dengan ilmu penge-tahuan umum untuk mengembangkan dan meningkatkan kemampuan santri sehingga dapat bersaing dalam dunia global. Misalnya saja didalam praksis pembelajaran pesantren ada bimbingan belajar bahasa Inggris, lifeskill maupun pelatihan-pelatihan. 
Santri adalah sebutan peserta didik dalam lingkungan pesantren. Azra dalam Taufiqurrohman (2015),

the pesantren is a residential shcool decicated to the transmission of the classical islamic sciences, including study of the Qur'an and hadith, jurisprudence (fiqh), Arabic grammar, mysticism (tasawwuf), and the Arabic sciences (alat)). A typical pesantren complex consists of a mosque, study rooms, dormitories, and kyai's (the islamic scholar who builds and leads the pesantren.

Pesantren adalah tempat sebagai suatu sekolah untuk menyalurkan ilmu agama, meliputi belajar qur'an dan hadist, fiqh, bahasa Arab, ilmu tasawwuf, ilmu alat. Elemen-elemen dalam pesantren yaitu terdapat masjid, tempat belajar, asrama dan kyai sebagai seorang pengasuh dan pembimbig dalam pesantren.

Sedangkan menurut Madjid (1997:20), santri dalam agama hindu berasal dari kata cantrik yang berarti orang-orang yang ikut belajar dan mengembara dengan empu-empu ternama. Namun, ketika diterapkan dalam agama Islam kata cantrik berubah menjadi santri yang berarti orang-orang yang belajar kepada guru agama.

Jurnalistik, sebagai bagian inherent dari proses pembelajaran, merupakan kegiatan yang dapat memperluas informasi dan wawasan santri dalam mempelajarinya sehingga dapat pula mengubah pandangan masyarakat terhadap lulusan pesantren.

Jurnalisme santri muncul karena beberapa hal. Salah satunya adalah adanya kekecewaan publik terhadap media yang seringkali mengalami kelunturan idealisme, bahkan memproduksi kabar bohong. Saat ini khalayak merasa idealisme media mainstream yang diharapkan oleh khalayak dapat berpihak kepada masyarakat luas dan menjunjung kebenaran, lalu menjadi tidak lagi bisa secara konsisten mengusung idealisme kebenaran tersebut. 
Peran jurnalisme santri melalui internet tampak dapat melahirkan perubahan yang besar. Selain di media sosial yang berbasis internet dan telepon genggam, jurnalisme santri juga tentunya dapat disalurkan melalui media konvensional, seperti: selebaran dan majalah dinding serta siaran radio atau via pendekatan pencerita/story teller yang dapat lebih efektif menyampaikan pesan-pesan kepada masyarakat yang masih mendapat kesulitan dalam kemampuan baca tulis.

Praktik jurnalisme santri adalah murni aktivitas yang tidak dikendalikan oleh pihak manapun. Dengan demikian, semua kegiatan jurnalistik untuk mencari, mengumpulkan, melaporkan, menganalisa, menyebarkan informasi dan berita, dan dilakukan secara mandiri.

Peran aktif para jurnalis santri adalah melakukan kegiatan jurnalisme yaitu mencari, mengolah, dan menyiarkan informasi. Sementara sejalan dengan percepatan teknologi, aktivitas jurnalistik ini bisa juga dilakukan oleh masyarakat umum. Mereka mencari, mengolah informasi dan membagikannya secara luas kepada masyarakat umum lainnya.

Dalam jurnalisme santri, sedikitnya memiliki landasan kuat tentang etika komunikasi dalam ajaran Islam . Etika atau akhlaq dapat mengarahkan prilaku berkomunikasi secara santun, jujur dan tidak merugikan orang lain. Hal ini dapat menjadi perisai agar terhindar dari menyebarkan dan memberikan informasi hoax. Di sisi lain dapat menangkal hoax ketika menerima pesan. Pandangan semacam ini jelas didasari suatu keyakinan seorang muslim bahwa seluruh prilaku dalam segala perikehidupan dianggap mengandung unsur-unsur dari sumber ajaran Islam (al-Qur'an, hadits, ijma' dan qiyas). Sumber-sumber hukum inilah yang mengarahkan seorang muslim dalam menilai baik dan buruk dalam berkomunikasi. 
Munculnya genre Jurnalisme Santri (santri journalism) setelah Jurnalisme Kenabian (Prophetic Journalism) dibarengi dengan tampilnya sejumlah penulis di media dengan latar belakang santri seperti Habiburrahman El-Sirozi, Mohammad Farid Fad, Prof Dr H Ahmad Rofiq MA, Dr H Abu Rohmat MAg, Dr H Mohammad Adnan MA, Drs H Ali Mufiz MPA, Ulil Abshar Abdalla, Ngatawi Al-Zastrouw dan lain-lain makin memberikan keyakinan dan kepercayaan masih ada secercah harapan untuk menikmati sumber bacaan yang sehat dan bergizi di masa yang akan datang.

Setidaknya ada empat pilar dasar keunggulan jurnalistik santri yaitu Siddiq (benar), Amanah (bisa dipercaya), Tabligh (menyampaikan) dan Fathanah (cerdas). Jurnalisme santri menitikberatkan pada pengembangan akhlakul karimah, meneladani akhlak dan perilaku mulia para nabi dan rasul dari semua agama. ${ }^{2}$

Prinsip pertama, sidiq. Berarti benar, lurus, jujur, berpedoman pada nurani, sabar, dan konsisten. Jurnalis yang sidiq adalah pewarta yang jujur kepada Tuhan, diri sendiri (nurani), orang lain, dan jujur terhadap tugas yang dijalani. Kebalikan dari sidiq adalah dusta, artinya berbohong, tingkah laku bertentangan dengan ucapan, serta lebih mengutamakan kepentingan pribadi daripada golongan.

Prinsip kedua, amanah. Berarti professional, terpercaya, berkomitmen, dan bertanggung jawab yang tinggi kepada Tuhan, masyarakat serta berperilaku secara adil. Amanah juga memiliki arti Wara' (hati-hati) dan Zuhud (tak terpedaya kehidupan dunia). Kebalikan dari amanah adalah khianat, yang berarti mengingkari kesepakatan dan janji, serta tidak bertanggung jawab terhadap informasi yang diproduksinya.

\footnotetext{
${ }^{2}$ Agus Fathuddin Yusuf, Jurnalistik Santri Semakin Diminati, Suara Merdeka, 24 September 2018.
} 
Prinsip ketiga, tabligh. Berarti mengajak orang lain melakukan kebaikan dan menjauhi kejahatan (amar makruf nahi munkar), berkomunikasi asertif, dan efektif. Perilaku jurnalis santri yang tabligh antara lain adalah berani menyatakan kebenaran dan bersedia mengakui kekeliruan. Apa yang benar dikatakan benar, apa yang salah dikemukakan salah. Jika tidak mampu menyatakan tidak mampu, jika tidak tahu menyatakan tidak tahu. Kebalikan dari tabligh adalah menyembunyikan, artinya menyembunyikan informasi, sulit memahami dan dipahami orang lain.

Prinsip keempat, fathonah. Berarti cerdas yang dibangun karena ketaqwaan kepada Tuhan, mampu menjadi problem solver, dan mempunyai keterampilan yang teruji. Perilaku pewarta yang fathonah terekspresi pada etos kerja dan kinerja pemberitaannya yang memiliki keterampilan yang teruji dan terampil. Kebalikan dari fathonah adalah syufaha/bodoh, mempunyai wawasan yang sempit, tidak bisa membedakan hal yang baik dan buruk, halal dan haram, haq dan batil dalam bertindak, serta hanya berorientasi pada materi dan hal-hal duniawi.

\section{Kesimpulan}

Dari uraian di atas, dapat disimpulkan bahwa ditengah maraknya berita yang bernarasi kebohongan, jurnalisme santri merupakan kebutuhan mendesak (dharuri) yang tak bisa ditawar lagi. Menyiapkan generasi santri yang tanggap literasi digital adalah solusi yang tak terhindarkan.

Diharapkan melalui jurnalisme santri, lensa penerawangan publik dapat diarahkan untuk memotret fakta dengan angle yang tepat. Dengan demikian, optik publik tidak lagi terlamurkan oleh miopia isu-isu laten primordialisme dan komunisme. 
Namun demikian, jurnalisme santri tentu punya keterbatasan. Keterbatasan tersebut meliputi lemahnya kemampuan jurnalisme santri, lemahnya keterampilan menyajikan berita, mengingat sumberdaya santri bukan berlatar belakang pendidikan jurnalistik murni. Oleh karena itu, diperlukan kerjasama multipihak untuk meningkatkan kapasitas santri agar dapat melakukan kegiatan jurnalisme santri ini.

\section{Daftar Pustaka}

Ermanto. 2005. Wawasan Jurnalistik praktis, peluang dan tantangan wartawan kreatif. Yogyakarta : Cinta Pena.

Ermanto. 2005. Menjadi Wartawan Handal Dan Profesional. Cinta Pena. Yogyakarta. Madjid, Nurcholis. 1997. Bilik-bilik pesantren, sebuah potret pengalaman. Jakarta: Paramadina.

Poerwandari, Kristi, Gaduh di Media. Kompas. Edisi 11 Februari 2017.

Romli, A. Sa. M. 2009. Bahasa Media: Panduan Praktis Bahasa Jurnalistik. Cetakan Pertama. Bandung: Batic Press.

Sutarto, Joko.2013. Manajemen Pelatihan.Yogyakarta : Deepublish.

Taufiqurrahman.2015. Pesantren literature a form of ideological discourse countening comunism. International Jurnal of Indonesian Studies. Vol : 01 No.2 128-140.

Wahyudi JB. 1996. Dasar-dasar jurnalistik radio dan televisi. Jakarta: Pustaka Utama Grafiti.

Yusuf, Agus Fathuddin, Jurnalistik Santri Semakin Diminati, Suara Merdeka, 24 September 2018. 